\title{
Synthesis and characterization of Tali Bamboo Particle Reinforced Polyester Composites
}

\author{
Martijanti $^{1,2, *}$, Ariadne L. Juwono ${ }^{1}$, Sutarno $^{3}$ \\ ${ }^{1}$ Department of Physics, Faculty of Mathematics and Natural Sciences, Universitas Indonesia (UI), Depok, 16424, \\ Indonesia \\ ${ }^{2}$ Department of Mechanical Engineering, Faculty of Manufacturing Technology, \\ JenderalAchmadYaniUniverstity (Unjani), Cimahi, Indonesia. \\ ${ }^{3}$ Department of Metallurgy Engineering, Faculty of Manufacturing Technology, JenderalAchmadYani University \\ (Unjani), Cimahi, Indonesia. \\ * Corresponding author: martijanti@lecture.unjani.ac.id
}

\begin{abstract}
Tali Bamboo is a potential natural fiber for reinforcement environment friendly composites. Synthesis and characterization of particle reinforced polyester composites aimed to reveal the mechanical properties as the main requirements in applications for structural composites. The parameters of the composite synthesis process varied the particle sizes of 50, 100, and 250 mesh, with each mesh varying the volume fractions of 10,20 , and $30 \%$ bamboo particle, respectively. Characterization included tensile and flexural tests, as well as Scanning Electron Microscope observation.. Characterization results showed that tensile strength in a range of $5.69-23.89 \mathrm{MPa}$, yield strength 2.97 $19.70 \mathrm{MPa}$, elongation $1.07-11.01 \%$ and flexural strength 21.71 - 56.05 MPa. Based on the results, the Tali Bamboo polyester composites met the requirements for structural composites according to SNI 03-2105-2006. SEM analysis showed the presence of bonding interfaces of bamboo particle dispersed well into the matrix. this had an effect on increasing the tensile strength, yield strength and flexural strength of Tali Bamboo particle reinforced polyester composites.
\end{abstract}

Key words: Tali Bamboo, polyester, Structural Composites, Flexural and Tensile Properties.

\section{INTRODUCTION}

Bamboo is a source of natural fiber with abundant availability and with limited application to meet needs such as houses, walls, ornaments, traditional equipment and even consumed in the form of bamboo shoots. It has the potential to replace polymer fibers made from the petroleum fraction, which are more environmentally friendly and biodegradable in nature.

This composite material can be applied to various functions such as vibration dampers, bio-filter, thermal insulators, vehicle accessories and lightweight structures. The economic value and function of bamboo can be increased through the diversification of natural polymer fiber products into bio-composites [1], [2] for various lightweight structure applications [3], sound vibration dampers [4], biofilters [5], and thermal [6].

From various research and development of this diversification potential it is very prospective because of the superior mechanical properties of bamboo, namely low density i.e. 0.8-1.5 gr/ $\mathrm{cm}^{3}$, tensile strength of 500-575 MPa, high elastic modulus of 27-40 GPa.Tensile strength and composite modulus of fibers extracted by steam explosion increased by 15-30\% with polypropylene matrix [7][8]. In other words, critical to quality (CTQ) natural fiber composites are the tensile strength of a single polymer fiber and adhesion to the matrix, either in the form of a thermoplastic matrix and/or thermosetting [9].

Research on bamboo fiber composites has been conducted by varying the volume fraction, the type of matrix both thermosetting and thermoplastic, the shape and size of the fiber, the orientation of the fiber, resulted in an increase in the mechanical properties of the composite. Research on bamboo fiber composites by varying the volume fraction [10]; the type of matrix both thermosetting and thermoplastic [11][12] [13], the shape and size of the fiber [14]; [15]; [16]; [17], the orientation of the fiber [18], resulted in an increase in the mechanical properties of the composite Mechanical properties play an important role which is an engineering design requirement for structural materials and other engineering fields.

The bamboo based composite is very prospective to be implemented in various application to replace parts and dies [19][20], although some research should be further developed. Different natural materials have been explored, for example [21].

In general, the tensile strength, $\sigma_{\mathrm{s}}$ be experimentally determined by Eq. (1). 
Tensile strength, $\sigma_{\mathrm{s}}=\frac{\text { Maximum tensile load applied }}{\text { Orginal cross section area }}=\frac{\mathrm{P}_{\max }}{\mathrm{A}}$

The unit used for tensile strength is $\mathrm{N} / \mathrm{m}^{2}$.

For composite materials, tensile strength as stated in Eq. (2) using rule of mixtures is a method of approach to approximate estimation of composite material properties. Based on an assumption that a composite property is the volume weighed average of the phases (matrix and dispersed phase) properties, i.e. computes the composite stress composite by the fiber volume fraction, stress composite, matrix volume fraction and matrix stress.

$$
\sigma_{\mathrm{c}}=\sigma_{\mathrm{m}} \mathrm{v}_{\mathrm{m}}+\sigma_{\mathrm{f}} \mathrm{v}_{\mathrm{f}}
$$

where $\sigma_{\mathrm{c}}$ is tensile strength composite, $\sigma_{\mathrm{m}}$, volume fraction matrix, $\mathrm{v}_{\mathrm{m}}$, and tensile fiber $\sigma_{\mathrm{f}}$ and volume fraction fiber, $\mathrm{v}_{\mathrm{f}}$. Flexural strength is determined using three point simply supported flexural equipment .In a conventional test, flexural strength, F.S expressed in MPa and given in Eq. (3).

$$
F \cdot S=\frac{3 L P}{2 b d^{2}}
$$

Where $\mathrm{P}=$ the load applied to a sample of test, in Newton $\mathrm{l}=$ specimen length in $\mathrm{mm} ; \mathrm{b}=$ specimen width in $\mathrm{mm} ; \mathrm{d}=$ specimen thickness in $\mathrm{mm}$.

Data processing test results and presentation in chart form aimed to analyze inter and inter group variations as well as trends and evaluations. In charting used types of stock charts consisting of (1) high-low closed, (2) open-high-low close, (3) volume-high-low close, and (4) volume-open-high-low close such as shown by Figure 1 .
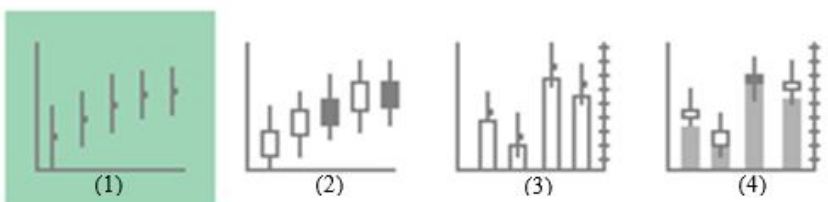

Figure 1: Stock Chart for data processing

Analysis of the distribution of data is in the maximum-minimum and average ranges and the data in the box chart are in the third quartile-first quartile as shown in Figure 2. The maximum-minimum range shows the distribution of variations in the group indicating variations in the product due to the process, while variations between groups indicates a tendency as a result of variations in independent variables.

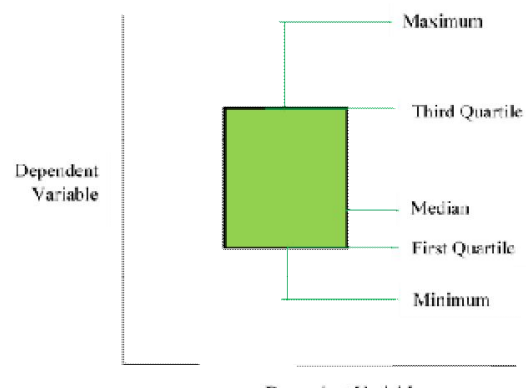

Depencenil Yariatil

Figure 2: Box chart for analysis the data processing result

Bamboo fiber composites in particle size using polyester matrix, as far as we know, only a few research have been conducted on these conditions and the data were inconsistent, so a study on bamboo particles reinforced composites was conducted. Tali bamboo has not been applied for composite reinforcement. The aims of the current research were to obtain consistent mechanical values of bamboo particles reinforced polyester composites and these composites were to be applied in structural and other engineering fields. Characterization was a focused in mechanical properties, consisting of tensile strength, yield strength, elongation, flexural strength and the composite's morphology. The tensile strength values were referred to SNI03-2105-2006.

\section{EXPERIMENTAL PROCEDURE}

The process of synthesis, characterization, and compilation of bamboo-polyester composite bamboo is shown in Figure 3.,

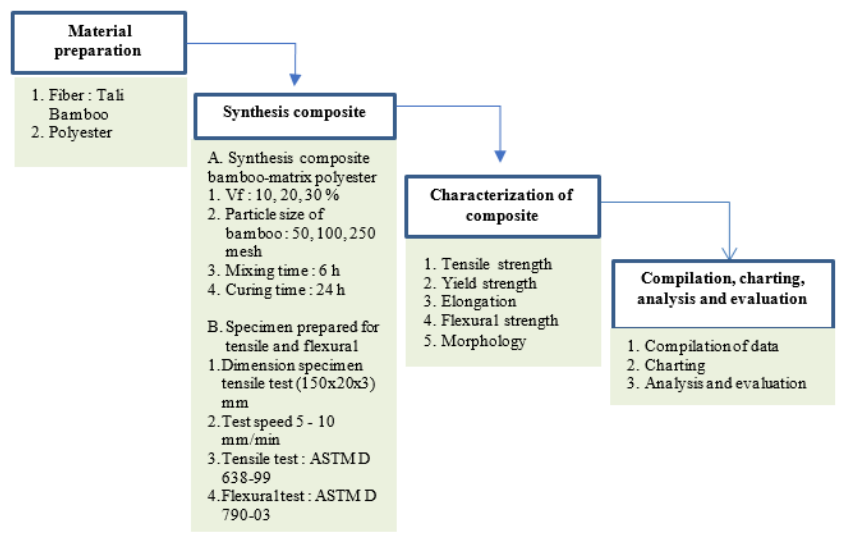

Figure 3: Synthesis and characterization of Tali Bamboo particle reinforced-polyester composite

\subsection{Material}

Material for composite synthesis consists of Tali Bamboo with particle sizes of 50, 100, 250 mesh and polyester matrix. The Tali Bamboo extraction process was carried out in an autoclave at a temperature $120^{\circ} \mathrm{C}$ with a pressure of $0.5 \mathrm{MPa}$ with $6 \% \mathrm{NaOH}$ solution and extraction time 2 hours. Tali Bamboo was then rinsed in water at a temperature of $(90-$ $957^{\circ} \mathrm{C}$. The Tali Bamboo dried it in an oven at a temperature of $105^{\circ} \mathrm{C}$ for 4 hours and then ground to finer granule by using a 
plate grinder. Polyester resins consist of two components, resin and hardener. Types of polyester resins are Yukalac 157 BQTN-EX ortho-phthalic Resin and Mekpo hardener (MetylEtyl Ketone Perokside) from PT Bratachem Bandung.

\subsection{Composite Synthesis Process}

Composite was synthesized from polyester matrix with variations of 10, 20,30\% volume fraction for each size of Tali bamboo particle. Polyester matrix was a mixture of polyester resin and hardener with a ratio of 100:1. This mixture was stirred for 10 minutes at room temperature. Composite synthesis process was started by mixing Tali bamboo particle with this polyester matrix, pouring into a mold sample with a pressure of $0.05 \mathrm{MPa}$ for 6 hours at room temperature and then curing for 24 hours.

\subsection{Composite Characterization}

Tensile and flexural testing were carried out using Hung Ta Instrument Go.Ltd, type HT-8503 Universal Testing Machine, with a cross head speed of $10 \mathrm{~mm} /$ minute, a capacity of $100 \mathrm{KN}$ as shown in Figure 4. The tensile test referred to the ASTM standard D 638-99 and the flexural test referred to the D 790-03standard, of five specimens for each test. Whereas composite morphology was observed using Scanning Electron Microscope (SEM) JEOLJSM-6360, 15 $\mathrm{kV}$.

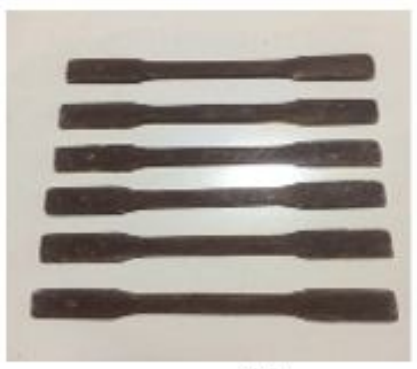

(a)

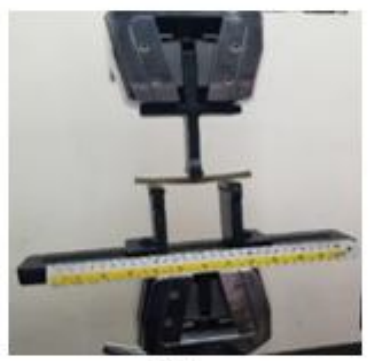

(b)

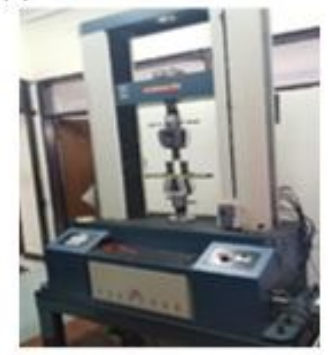

(c)

Figure 4: (a) tensile test specimens, (b) Flexural test, (c) Universal Testing Machine

\section{RESULTS AND DISCUSSION}

\subsection{Compilation and processing of test data}

Data compilation of mechanical properties testing results including tensile strength, flexural strength, and morphology, with size variations of 50, 100, and 250 mesh Tali Bamboo particle and volume fractions of 10, 20, and $30 \mathrm{wt} \%$ are presented in Figures 1, 2, and 3, Furthermore, analysis and evaluation were carried out by comparing with the results of previous researchers.

Correlation between tensile strength to the the size of Tali Bamboo particle 50, 100 and 250 mesh at 10, 20, and 30\% volume fraction of TaliBambo particle is shown in Figure 5. Based on Figure 5, on the size of Tali Bamboo particle 50 mesh, the tensile strength ranges 5.69-13.31 MPa for $10 \%$ volume fraction, $15.85-19.17 \mathrm{MPa}$ for $20 \%$ volume fraction, and $17.17-23.82 \mathrm{MPa}$ for $30 \%$ volume fraction. While the size of 100 mesh tensile strength ranges from $8.77-13.17$ MPa for $10 \%$ volume fraction, 13.47 - $15.65 \mathrm{MPa}$ for $20 \%$ volume fraction, 17.17 - 23.82 MPa for $30 \%$ volume fraction. The size of 250 mesh tensile strength ranges from 5.80 - 13.89 MPa for $10 \%$ volume fraction, $15.61-21.25$ for $20 \%$ volume fraction and $20.83-25.39$ for $30 \%$ volume fraction.

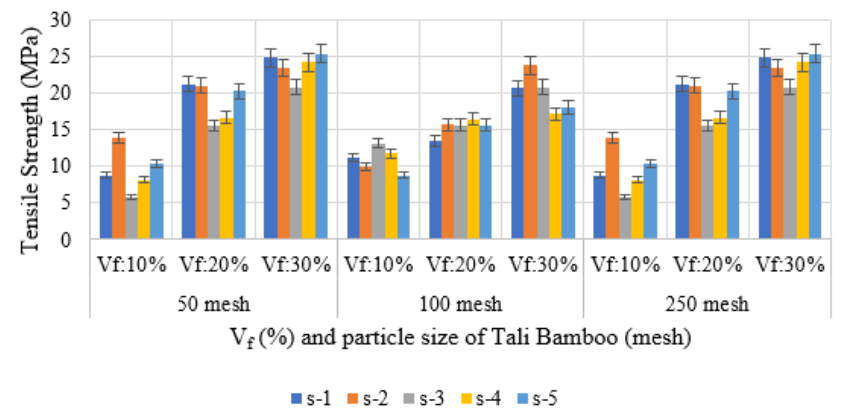

Figure 5: Correlation of tensile strength versus variation of volume fraction $\mathrm{V}_{\mathrm{f}}(\%)$ on size variation (mesh)

To clarify Figure 5, the size of Tali Bamboo particle (mesh) and the volume of fraction that processed in the form of charting as shown in Figure 6. Based on Figure 6., it is clear that the increase in size and the volume fraction of bamboo particle fraction increases the tensile strength by $10.11 \mathrm{MPa}$ for volume fraction 10\%, 16.95 MPa for volume fraction $20 \%$ and $20.95 \mathrm{MPa}$ for volume fraction $30 \%$ in size Tali Bamboo particle $50 \mathrm{mesh}$, the tensile strength by $10.98 \mathrm{MPa}$ for volume fraction $10 \%, 15.38$ for volume fraction $20 \%$ and 18.98 $\mathrm{MPa}$ for volume fraction $30 \%$ in size Tali Bamboo particle 100 mesh, the tensile strength $9.41 \mathrm{MPa}$ for volume fraction 10\%, $18.98 \mathrm{MPa}$ for volume fraction $20 \%$ and 23.76 MPa for volume fraction $30 \%$ in size Tali Bamboo particle 250 mesh.

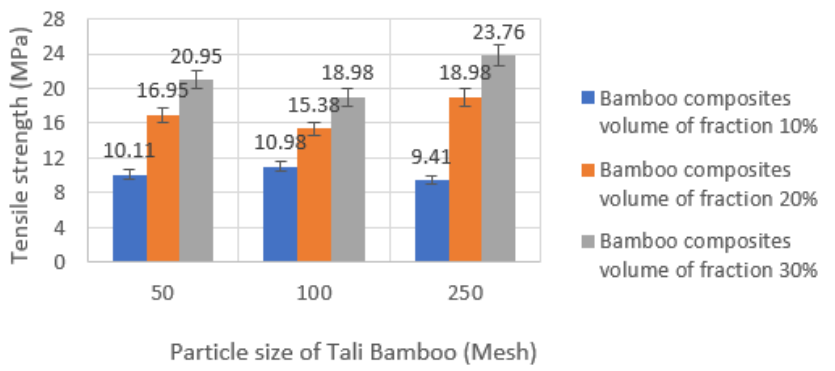

Figure 6: Correlation tensile strength versus volume fraction on size variation 
This is consistent with equation (2) and the results of research from previous researchers such as [10][11] [12] [13] [22][23]. When polyester reinforced by particle bamboo this property was improved greatly, where the particle Tali Bamboo withstand the maximum part of loads and by consequence raised the strength of composite material. The tensile strength increased with the particle Tali Bamboo percentage addition increased, where theTali Bamboo particles were distributed on large area in the polyester.

Based on Figure 6, the tensile strength composite of Tali Bamboo particle reinforced polyester composites occurs in 250 mesh of $25.39 \mathrm{MPa}$ with $30 \%$ volume fraction, and a minimum of 5.6 MPa of 50 mesh Tali Bamboo particle size with $10 \%$ volume fraction. Thus, the size and volume fraction of the Tali Bamboo particle have an effect on increasing the tensile strength of the composite. The results of this composite tensile strength study were in accordance with research conducted by Hui [15] which is $1.53 \mathrm{MPa}$ at 20 mesh particle size and $7.50 \mathrm{MPa}$ with 40 mesh particle size. The results indicated that the optimal size of bamboo was 40 mesh, because a big size of bamboo would affect the tensile strength of bamboo reinforced composites. The optimal size of particle Tali Bamboo was 250 mesh, because when the size of particle bamboo increased, the tensile strength of the composite increased. These bamboo particleswere distributed on large area in the matrix, thus increasing bonding between particle bamboo and matrix to increasing the adhesive strength.

The correlation between the size of Tali Bamboo particle 50, 100 and 250 mesh at 10, 20, and 30\% volume fraction of Tali Bamboo particle on yiled strength is shown in Figure 7.

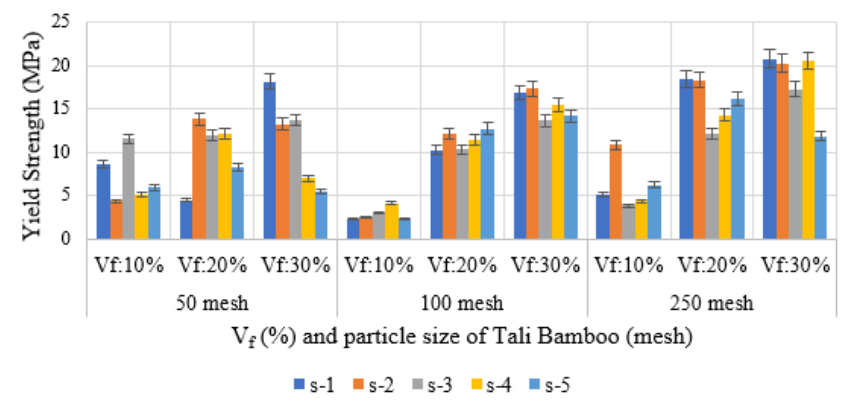

Figure 7: Correlation yield strength versus volume fraction on size variation (mesh)

At the 50 mesh size, yield strength ranges from $4.33-11.52$ $\mathrm{MPa}$ for $10 \%$ volume fraction, $4.48-13.86 \mathrm{MPa}$ for $20 \%$ volume fraction, $17.17-23.82 \mathrm{MPa}$ for $30 \%$ volume fraction. While the size of 100 mesh tensile strength ranges from 8.77 13.17 MPa for the 10\% volume fraction, $13.47-15.65 \mathrm{MPa}$ for the $20 \%$ volume fraction, $17.17-23.82 \mathrm{MPa}$ for the $30 \%$ volume fraction. The size of 250 mesh tensile strength ranges from 5.80 - 13.89 MPa for 10\% volume fraction, 15.61 -21.25 for $20 \%$ volume fraction and $20.83-25.39$ for $30 \%$ volume fraction. Yield strength of Tali Bamboo particle reinforced polyester composites maximum value at 250 mesh fiber size with $30 \%$ fiber volume fraction with $19.70 \mathrm{MPa}$ value and minimum value at 100 mesh particle size with $10 \%$ volume fraction of $2.97 \mathrm{MPa}$. In other words, the larger particle size Tali Bamboo, the higher the yield strength. The Tali Bamboo particles withstood the maximum part of loads and by consequence raised the strength of composite material. The smaller Tali Bamboo particles causes the larger surface area, thus increasing the adhesive strength between particles, thus to increase in yield strength.

The correlation between the size of Tali Bamboo particle 50, 100 and 250 mesh at 10,20, and 30\% volume fraction of Tali Bamboo particle to elongation is shown in Figure 8.Based on Figure 8., size 50 mesh, the extension ranges from 2.60 $10.34 \%$ for the $10 \%$ volume fraction, $1.51-5.93 \%$ for the $20 \%$ volume fraction, $3.27-9.66 \%$ for the $30 \%$ vol fraction. While the size of the extension of 100 mesh ranges from 1.37 $11.01 \%$ for the $10 \%$ volume fraction, $2.15-4.33 \%$ for the $20 \%$ volume fraction, $2.99-6.53 \%$ for the $30 \%$ volume fraction. The size of 250 mesh tensile strength ranges from $1.07-2.93 \%$ for the $10 \%$ volume fraction, $1.22-1.72 \%$ for the $20 \%$ volume fraction and $1.31-1.81 \%$ for the $30 \%$ volume fraction.

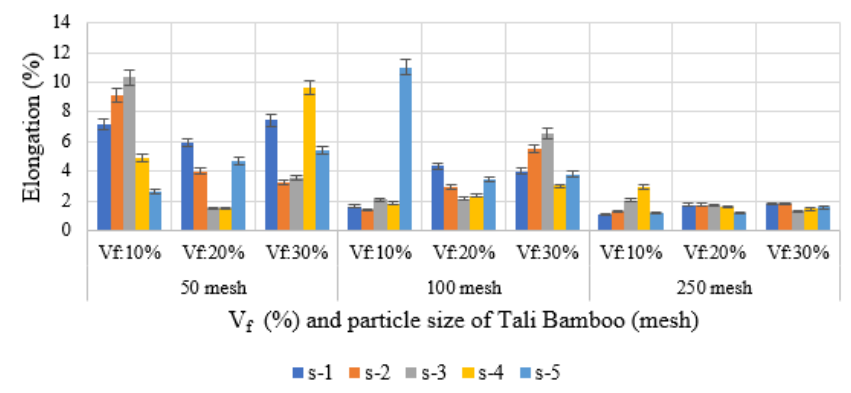

Figure 8: Correlation elongation versus volume fraction on size variation (mesh)

Elongation of the maximum value at 100 mesh fiber size with $10 \%$ volume fraction of $11.01 \%$ and the minimum value of 250 mesh fiber size at $10 \%$ volume fraction of $1.07 \%$. Thus, the elongation value varies greatly and the increase in fiber volume fraction does not have an effect on increasing elongation, and tends to be but inversely proportional to tensile strength and yield strength. Because reinforcement, which had less ductile properties but was stronger, the increase in fiber volume fraction was distributed on large area in matrix , there was to decreases in ductile material composite. Ductility of the composites was characterized by reduction in the elongation value.

The correlation between flexural strength and the size of Tali Bamboo particle of 50, 100 and 250 mesh at 10, 20, and 30\% volume fraction of Tali Bamboo particle is shown in Figure 9. Based on Figure 9, it can be seen that at 50 mesh size, flexural strength ranges from $21.50-27.44 \mathrm{MPa}$ for $10 \%$ volume fraction, 31.11 - 40.19 MPa for 20\% volume fraction, 34.07 $47.04 \mathrm{MPa}$ for $30 \%$ volume fraction. Whereas the size of 100 mesh flexural strength ranges from 28.09 - $34.68 \mathrm{MPa}$ for 
$10 \%$ volume fraction, $31.33-45.80 \mathrm{MPa}$ for $20 \%$ volume fraction, $37.41-50.37 \mathrm{MPa}$ for $30 \%$ volume fraction. The size of 250 mesh tensile strength ranges from $21.71-32.19 \mathrm{MPa}$ for $10 \%$ volume fraction, $35.43-38.78$ for $20 \%$ volume fraction and $41.60-56.05$ for $30 \%$ volume fraction.

When Figure 9 is compared to Figure 5 there is a similarity in the pattern which shows that at the same mesh size both 50 , 100 and 250 mesh the increase in volume fraction increases the flexural strength. The increase in fiber volume fraction is directly proportional to the increase in flexural strength of bamboo composites. However, variations in mesh size at the same volume fraction tend to be no difference. The smaller particle Tali Bamboo causes the larger surface area, thus increasing the adhesive strength between particles and increasing bonding particle in matrix to increases in flexural strength.

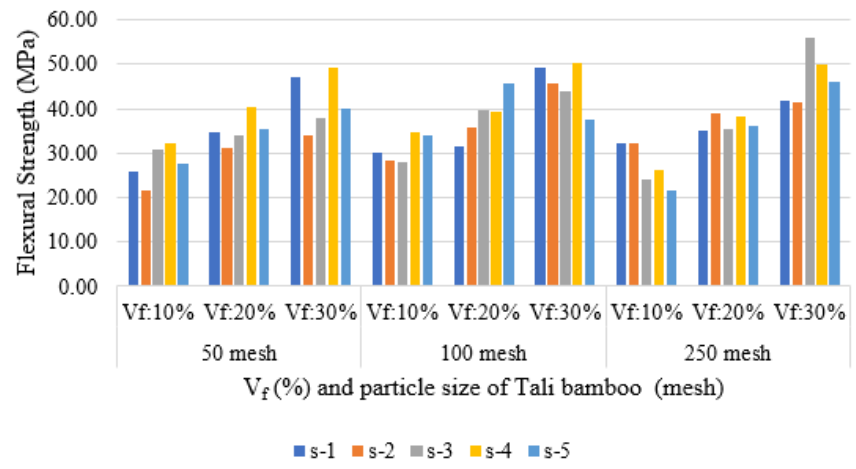

Figure 9: Correlation flexural strength versus volume fraction on size variation (mesh)

A summarized mechanical properties of Tali bamboo particle reinforced polyester composites with volume fraction and size variations is presented in Table 1. Based on Table 1, when the volume fraction of fiber increases at the same mesh size of bamboo particles, the tensile strength, flexural strength and yield strength values also increase.

Table 1 Summarized Mechanical Properties of Tali Bamboo Particle with volume fraction on size variation

\begin{tabular}{|c|c|c|c|}
\hline Materials & $\begin{array}{c}\text { Tensile } \\
\text { Strength } \\
(\mathrm{MPa})\end{array}$ & $\begin{array}{c}\text { Flexural } \\
\text { Strength } \\
(\mathrm{MPa})\end{array}$ & $\begin{array}{l}\text { Yield Strength } \\
(\mathrm{MPa})\end{array}$ \\
\hline \multicolumn{4}{|c|}{ Tali Bamboo Particle + Polyester (50 mesh) } \\
\hline $\mathrm{V}_{\mathrm{f}}=10 \%$ & 10.11 & 27.44 & 11.52 \\
\hline $\mathrm{V}_{\mathrm{f}}=20 \%$ & 16.95 & 40.19 & 13.86 \\
\hline$V_{f}=30 \%$ & 20.95 & 47.04 & 23.82 \\
\hline \multicolumn{4}{|c|}{ Tali Bamboo Particle + Polyester (100 mesh) } \\
\hline $\mathrm{V}_{\mathrm{f}}=10 \%$ & 10.98 & 34.68 & 13.17 \\
\hline $\mathrm{V}_{\mathrm{f}}=20 \%$ & 15.38 & 45.80 & 15.65 \\
\hline $\mathrm{V}_{\mathrm{f}}=30 \%$ & 18.98 & 50.37 & 23.82 \\
\hline \multicolumn{4}{|c|}{ Tali Bamboo Particle + Polyester (250 mesh) } \\
\hline$V_{f}=10 \%$ & 9.41 & 32.19 & 13.89 \\
\hline $\mathrm{V}_{\mathrm{f}}=20 \%$ & 18.98 & 38.78 & 21.25 \\
\hline $\mathrm{V}_{\mathrm{f}}=30 \%$ & 23.76 & 56.05 & 25.39 \\
\hline
\end{tabular}

A compilation of tensile test results from previous researchers for bamboo fiber composites and polyester matrix is presented in Table 1. Based on Table 2, it is seen that in general the tensile strength of composites with lower particle, reaches 25.39 MPa maximum compared to when it is in the form of fiber which reaches $169 \mathrm{MPa}$, whereas for flexural strength it reaches $56 \mathrm{MPa}$ compared to $221 \mathrm{MPa}$.

Table 2:.Tensile test comparison results

\begin{tabular}{|c|c|c|c|}
\hline Composite & $\begin{array}{l}\text { Tensile } \\
\text { Strength } \\
(\mathrm{MPa})\end{array}$ & $\begin{array}{c}\text { Flexural } \\
\text { Strength } \\
(\mathrm{MPa})\end{array}$ & Ref \\
\hline $\begin{array}{l}\text { Tali Bamboo } \\
\text { particle +Polyester } \\
(10,20,30)\end{array}$ & $\begin{array}{l}5.69- \\
25.39\end{array}$ & $\begin{array}{l}21.71- \\
56.05\end{array}$ & $\begin{array}{l}\text { [current } \\
\text { results] }\end{array}$ \\
\hline $\begin{array}{l}\text { Bamboo particle } \\
(50-150 \\
\text { micro)+matrix }\end{array}$ & $\begin{array}{c}1.70- \\
14.3 \\
\end{array}$ & $31.3-79.8$ & [24] \\
\hline $\begin{array}{l}\text { Bamboo particle } \\
+ \text { Fiber }(50: 50)+ \\
\text { Matrix }\end{array}$ & $23.5-33$ & $\begin{array}{c}106.5- \\
140.1\end{array}$ & [24] \\
\hline $\begin{array}{l}\text { Bamboo Fiber + } \\
\text { Matrix }\end{array}$ & $\begin{array}{l}23.1- \\
169.9\end{array}$ & $\begin{array}{c}130.1- \\
221.3\end{array}$ & [24] \\
\hline $\begin{array}{l}\text { Bamboo Short } \\
\text { Fiber }(1=2 \mathrm{~mm})+ \\
\text { Polyester } \\
(15,30,45)\end{array}$ & $\begin{array}{l}7.241- \\
15.601\end{array}$ & $\begin{array}{c}26.226- \\
38.989\end{array}$ & [25] \\
\hline $\begin{array}{l}\text { Bamboo Fiber + } \\
\text { Polyester }\end{array}$ & 126 & 161 & [22] \\
\hline $\begin{array}{l}\text { Bamboo Fiber + } \\
\text { Polyester }\end{array}$ & $74-97$ & $78-107$ & [26] \\
\hline
\end{tabular}

Comparisons of composite tensile and flexural strengths from various researchers are presented in Figures 10 and 11 respectively. Based on Figure 10., it can be seen that the bamboo fiber reinforced composites possess higher tensile strength compared the bamboo particle reinforced composites.

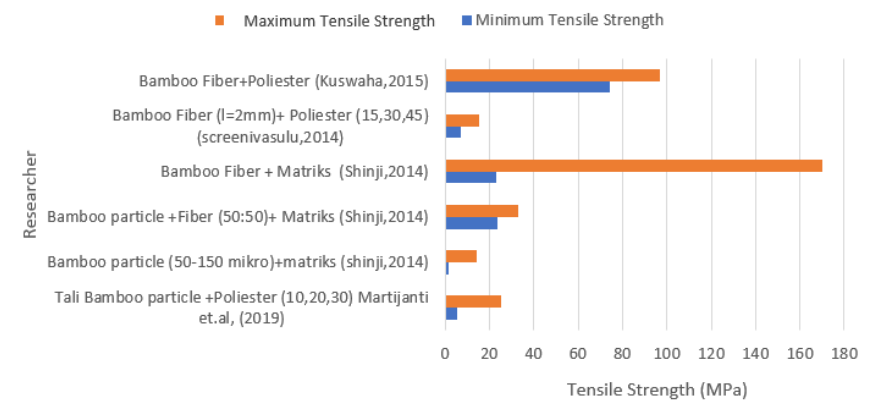

Figure 10: Comparison of tensile strengths of bamboo-polyester composites from different researchers

In the current research,Tali Bamboo particle reinforced composites with a polyester matrix has a minimum tensile strength value of 5.69 $\mathrm{MPa}$ and a maximum value of 25.39 $\mathrm{MPa}$, while other studies have a minimum value of $1.70 \mathrm{MPa}$ and a maximum value of 15,601 . This indicated both the value of minimum and maximum tensile strengths of the current 
study is greater than previous studies. The minimum and maximum tensile strengths compared to previous studies increased respectively $71.25 \%$ and $38.58 \%$. The minimum and the maximum tensile strength values of the current study were in the range of SNI 03-2105-2006 values (0.15 - 0.31) MPa.

As can be seen in Figure 11., similar to Figure 10, bamboo fiber reinforced composites possess greater flexural strength values compared to bamboo particle reinforced composites. In the current study, the Tali Bamboo particles reinforced polyester composites have a minimum flexural strength value of $21.71 \mathrm{MPa}$ and a maximum value of $56.45 \mathrm{MPa}$; while other studies have a minimum value of $26,226 \mathrm{MPa}$ and a maximum value of $79.86 \mathrm{MPa}$. This indicates both the minimum and maximum flexural strength values in the current study are lower compared to previous studies, but they are still in the range of values from previous studies. \%. The minimum and the maximum flexural strength values of the current study were in the range of SNI 03-2105-2006 values (5.1 - 30.6) MPa.

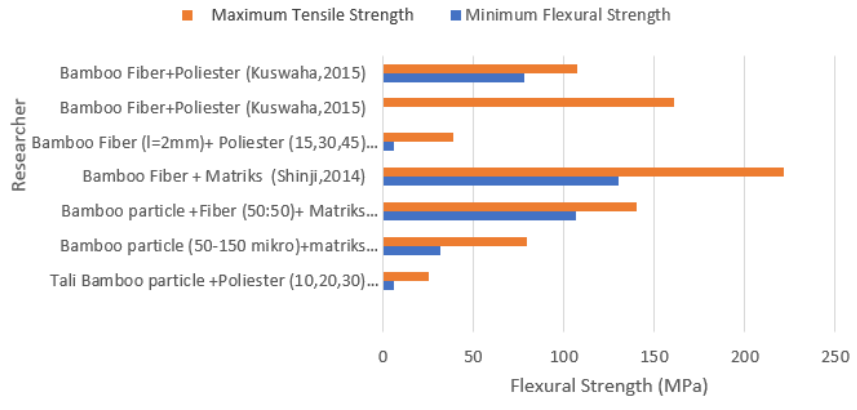

Figure 11:Comparison flexural strengths bamboo-polyester composites from different researchers

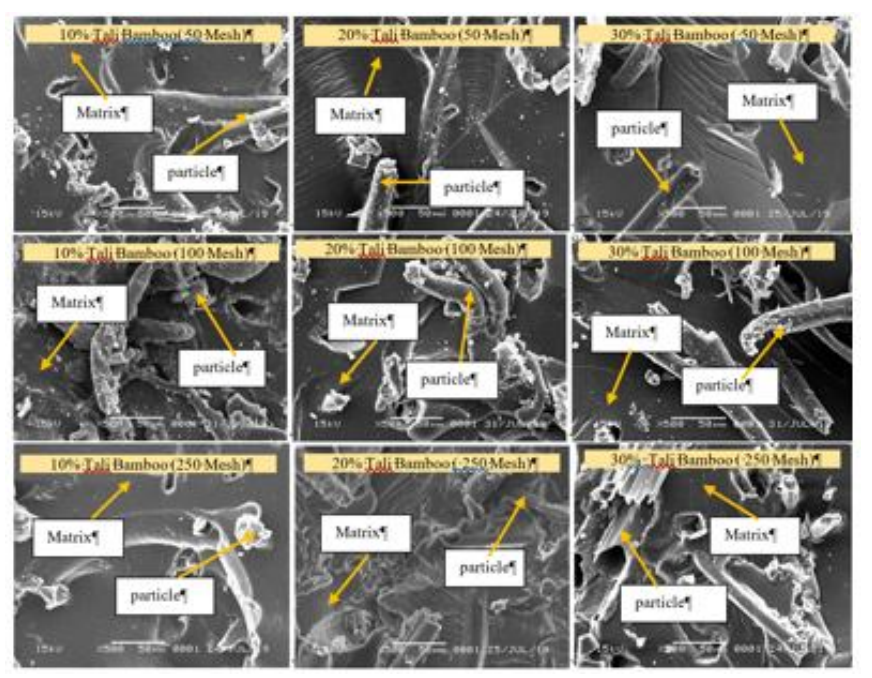

Figure 12: Morphology of Tali bamboo particle reinforced polyester composites with the variation of volume fractions (horizontal view) and the variation of particle size in mesh (vertical view)

\subsection{Morphology of Composites}

The correlation between the Tali Bamboo particle sizes of50,100 and 250 mesh at 10, 20 and $30 \%$ fraction volume and their morphologies was observed was exhibited on the SEM images in Figure 12.

Figure 12 shows the interface of a smooth slice prepared by saw, depicting the well dispersion of bamboo particles inside the polyester matrix. it was found that there was a possible compatibility between bamboo and polyester. As a result debonding between particle bamboo and matrix could occur to high interfacial strength, because the bamboo particle was well wetted by the matrix.

It is an evident that Tali Bamboo particle reinforced Polyester composites had good interface compatibility and good mechanical properties. The existence of proton donor-proton acceptor interactions between matrix and lignin chains of bamboo was one reason., There was also interactions occurred between hydroxyl or carbonyl group of lignin of bamboo and $-\mathrm{H}$ of matrix as reported by Hui et al. [15]. On the other hand, Figure 12 reflects a cross section of sharp flexural interface and demonstrates that some bamboo particles had been pulled out from matrix resin, and revealed probable bonding weakness between Tali bamboo particles.

\section{CONCLUSION}

Synthesis and characterization of Tali bamboo particle reinforced polyester composites, with variations in the size of bamboo particle 50, 100, and 250 mesh with varying volume fractions of 10,20, and 30 have been successfully carried out. Conclusions drawn from the characterization are as follows.

Increasing the volume fraction of fiber at the same mesh size of bamboo particle increased the tensile strength, yield strength and flexural strength. The increasing in mesh size at the same volume fraction increased both tensile strength, yield strength and flexural strength. Based on SEM observation results, it showed that there was a very good bond between the bamboo matrix and polyester matrix.

Based on the SNI 03-2105-2006 standard, the tensile and flexural strengths of Tali Bamboo particle reinforced polyester composite met the requirements of SNI.

\section{ACKNOWLEDGEMENT}

The financial support of the research has been supported by the Ministry of Research, Technology, and Higher Education, agreement letter number:

NKB-1824/UN2.R3.1/HKP.05.00/2019.

\section{REFERENCES}

1. Bogoeva $\square$ Gaceva, G., Avella, M., Malinconico, M., Buzarovska, A., Grozdanov, A., Gentile, G. and Errico, M.E. (2007), Natural fiber eco $\square$ composites. Polym Compos, 28: 98-107. doi:10.1002/pc.20270

2. Joshi,S.,V., Drzal,L., T., Mohanty, A.,K.,\& Arora, S. (2004). Are natural fibers composites environmentally superior to glass fiber composites? Composites: Part A. 35, 371-376 
3. Gibson, R., F. (2010). Review of recent research on mechanics of multifunctional composite materials and structures. Composite Structures, 92, 2793-2810.

4. Khalil, H. P. S. A., Bhat, I. U. H., Jawaid, M., Zaidon, A., Hermawan, D., \&Hadi, Y. S. (2012). Bamboo fibre reinforced biocomposites: A review. Materials and Design, 42, 353-368.

5. Reddy, N., \& Yang, Y. (2015). Natural Cellulose Fibers from Corn Innovative Biofibers from Renewable Resources. Springer Heidelberg New York. ISBN 978-3-662-45135-9 5-8.

6. Chattopadhyay, S., K., Khandal, R., K., Uppaluri, R., \&Ghoshal, A., K. (2011). Bamboo fiber reinforced polypropylene composites and their mechanical, thermal, and morphological properties. Journal of Applied Polymer Science, 119, 1619-1626

7. Qiang, J., Wei, Z., \&Wenbin, Y. (2018). Bamboo Conditions for Processing Bamboo Fiber with Combing Method. IOP Conf. Series: Materials Science and Engineering 381, 012033, doi:10.1088/1757-899X/381/1/012033

8. Gunawan, R., Yusi, S., \&Hermawan, J. (2019). The Tensile Strength of Petung Bamboo Fiber Reinforced Epoxy Composites: The Effects of Alkali Treatment, Composites Manufacturing, and Water Absorption. Series: Materials Science and Engineering , 547, 012043 , doi:10.1088/1757-899X/547/1/012043

9. Roslan., S. A. H., Rasid, Z. A.\& Hassan, M. Z. (2018). Bamboo reinforced polymer composite - A comprehensive review. IOP Conf. Series: Materials Science and Engineering, 344, ,012008, doi:10.1088/1757-899X/344/1/012008

10. Ali, I. A., Shaymaa, A.A., \&Abbass, H. (2015). Mechanical Properties of Recycled Bamboo Fibers Reinforced Composite. European Journal of Advances in Engineering and Technology, 2(4): 20-22, ISSN: 2394 $-658 \mathrm{X}$,

11. Sofyan, D., NPG, S., Agustinus, P. I., \&IKG, S. (2019). Tensile Properties of Bamboo Strip Reinforced-Epoxy Matrix Composite. IOP Conf. Series: Materials Science and Engineering, 508, 012055. IOP

Publishing doi:https://doi.org/10.1088/1757-899X/508/1/012055

12. M., Ramachandran., Sahas, B., Vishal, F., \&Pramod, R. (2015). Analysis of Bamboo Fibre Composite with Polyester and Epoxy Resin. International Journal on Textile Engineering and Processes, 1(4).

13. R.,S.,Wani., R, R., Shitole. (2017). Tensile Testing of Bamboo Fiber Reinforced Epoxy Composite. IOSR Journal of Mechanical and Civil Engineering (IOSR-JMCE) e-ISSN: 2278-1684,p-ISSN: 2320-334X PP. 07-11 www.iosrjournals.org 6th National Conference RDME 2017, 17-18 March 2017.DOI: 10.9790/1684-17010050711.

14. Wenwen, G., Ehsan,N., K., Xin,W., Weiyi,X., Ping,Z., Lei, S. \& Yuan, H.(2019).Processing bulk natural bamboo into a strong and flame-retardant composite Material. Industrial Crops \& Products,138,111478, https://doi.org/10.1016/j.indcrop.2019.111478.
15. Hui, W., Rui, C., Kui-chuan,S., Mehrdad, A., Xiang-qun, Q. (2008). Impact Response of Bamboo-Plastic Composites with the Properties of Bamboo and Polyvinylchloride (PVC). Journal of Bionic Engineering Suppl, 28-33.

16. L. Osorio, E. Trujillo, A.W. Van Vuure and I. Verpoest. (2019). Morphological aspects and mechanical properties of single bamboo fibers and flexural characterization of bamboo/epoxy composites. Journal of Reinforced Plastics and Composites,30(5), 396-408, DOI: 10.1177/0731684410397683jrp.sagepub.com

17. Sergio, N., M., Frederico., M., M., Fábio., d., O., B., Fernanda., S., d., L., \&Noan, T., S. (2014). Weibull analysis of the tensile strengthdependence with fiber diameter of giant bamboo, Materials Sciences and Applications, 5, 1011-1019, http://dx.doi.org/10.4236/msa.2014.514103

18. C. S.,Verma., Rajesh, P., R. S. Rana., and H. Mohit.(2017). Mechanical properties of bamboo laminates with other composites. Materials Today, Proceedings 4, 3380-3386.

19. Siswanto, W.A., Omar, B.(2008). Die surface design optimization accommodating springback assisted by an automatic surface generator, International Journal of Material Forming, 2(SUPPL. 1), 797-800.

20. Darmawan, A.S., Siswanto, W.A., Sujitno, T. (2013). Comparison of commercially pure titanium surface hardness improvement by plasma nitrocarburizing and ion implantation, Advanced Materials Research, 789, 347-351.

21. Latha, M.S., Naveen Kumar, B.M., Madihalli, R., Deepika, R., Rudraswamy, M.P. (2020). Strength characteristics of high performance concrete using bagasse ash and slag sand, International Journal of Emerging Trends in Engineering Research, 8(6), 2486-2489.

22. Kushwaha, P., K., \& Kumar, R. (2015). The studies on performance of epoxy and polyester based composites reinforced with bamboo and glass fibers. J ReinfPlast Compos, vol. 29, pp. 1952- 1962

23. Martijanti, Sutarno, Juwono, A.L.(2020). Bamboo fibers, fabrication of bamboo fiber reinforced composites, and their mechanical properties-a review, International Journal of Emerging Trends in Engineering Research, 8(6), 2346-2359.

24. Shinji, O. (2014). Mechanical Properties of Uni-Directional Long Bamboo Fiber/Bamboo Powder CompositeMaterials.Materials Sciences and Applications, 5, 1011-1019

http: //dx.doi.org /10.4236/msa.2014.514103

25. S.Sreenivasulu, Chennakeshava, R. (2014). Mechanical Properties Evalution of Bamboo Fiber Reinforced Composite Materials. International Journal of Engineering Research,3(1), 187-194.

26. Kushwaha, P., K., \& Kumar, R. (2014). Studies on performance of acrylonitrile pretreated bamboo reinforced thermosetting resin composites. J ReinfPlast Compos, 1347-1352. 